\title{
Transciliary supraorbital keyhole approach in the management of aneurysms of anterior circulation: Operative nuances
}

\author{
Harjinder S. Bhatoe \\ Department of Neurosurgery, Command Hospital (SC) E Armed Forces Medical College, Pune - 411 040, Maharashtra, India
}

Address for correspondence:

Dr. Brig. Harjinder S. Bhatoe,

Department of Neurosurgery,

Command Hospital (Southern

Command), Pune - 411 040,

Maharashtra, India.

E-mail: hsbhatoe@gmail.com

PMID: 19934559

DOI: $10.4103 / 0028-3886.57812$

\begin{abstract}
Background: With improvement in neuroimaging, instrumentation and operative microscope optics, and with better understanding of microneuroanatomy, it is now possible to approach intracranial aneurysms of anterior circulation through a small eyebrow incision. Aim: The objective of the study is to highlight the advantages and limitations of transciliary supraorbital keyhole craniotomy for clipping of these aneurysms. Materials and Methods: We present our experience with 55 intracranial aneurysms in the anterior circulation in 52 consecutive patients ( 23 females and 29 males, age range 22-70 years) operated between 2003 and 2009. All these aneurysms were clipped by a supraorbital transciliary incision and a craniotomy measuring $2.5 \times 1.5 \mathrm{~cm}$. One patient required bilateral keyhole craniotomies for bilateral aneurysms. Results: Of the 52 patients, 37 patients were in Grade I/II, and the rest were in Grade III-IV. Clipping could be done in all the patients, and in twelve patients there was intraoperative rupture of the aneurysm. While there was a learning curve, no limitations were apparent, and none of the patients required revision of the procedure or wrapping. None of the patients had suboptimal clip application. Postoperative check angiogram showed obliteration of the aneurysm in all the patients. Patients with preoperative Grade I/II could be discharged from the hospital within seven days, and cosmetic result was excellent in all the patients. Four patients with preoperative Grade IV died in the postoperative period due to vasospasm. Conclusion: The transciliary supraorbital approach offers clipping of intracranial aneurysm in anterior circulation with low approach related morbidity as compared to standard approach.
\end{abstract}

Key words: Aneurysm, keyhole craniotomy, subarachnoid hemorrhage, transciliary

\section{Introduction}

Surgery for intracranial aneurysms has traditionally entailed large craniotomies, even in the post-microscope era. With improvement in optics, and re-introduction of neuroendoscopy, neurosurgeons have ventured into reducing the size of craniotomy required to clip aneurysms. Keyhole surgery for intracranial lesions has shown how a seemingly small incision ('band-aid' incision) can be adequate for operating on tumors and aneurysms. A number of reports concerning the surgery for intracranial aneurysms operated by keyhole approach have appeared recently. ${ }^{[1-6]}$ Supraorbital approach is an important portal of intracranial entry, which gives access not only to the anterior base, but also to the sellar and parasellar region, and to the vessels of the anterior circulation. Refinements in operative technique have led to almost all aneurysms of anterior circulation being amenable to clipping by supraorbital keyhole approach. We present our experience in the surgical management of these aneurysms in a two Armed Forces tertiary referral institution.

\section{Materials and Methods}

Between November 2003 and March 2009, all 52 consecutive patients with 55 intracranial aneurysms of anterior circulation admitted to the Department of Neurosurgery, Army Hospital ( $R$ and R) Delhi 
Cantt, New Delhi, and Armed Forces Medical College, Pune were included in this study. Patients with giant aneurysms of the internal carotid artery that required external carotid-internal carotid bypass were excluded from this group. There were 23 females and 29 males, with age ranging from 22 to 70 years. Their clinical grade on admission, and the location of aneurysms are given in Table 1 . All the patients were first admitted to a peripheral general hospital, where after undergoing computed tomography (CT) of brain, and initial management of subarachnoid hemorrhage (SAH) were referred to our hospital. Ten patients were admitted within $48 \mathrm{~h}$ of ictus, 30 patients were admitted within two weeks, 11 after two weeks and one patient who had undergone pterional craniotomy and clipping for middle cerebral artery (MCA) aneurysm elsewhere was referred to our hospital six months later with visualization of aneurysm on check angiography. All patients underwent CT brain for diagnosis of SAH and associated hydrocephalus, followed by four-vessel digital subtraction angiography (DSA) by transfemoral route [Figures 1a, 2a, 2b, 3a, 4a]. Twenty-five patients had anterior communicating artery

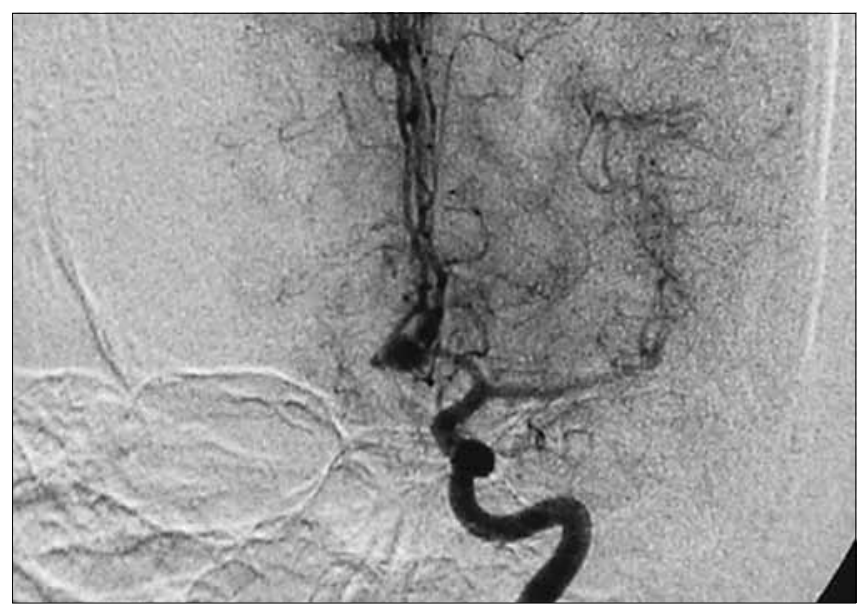

Figure 1a: Digital subtraction angiography showing anterior communicating artery aneurysm and both A2 segments fed by left A1

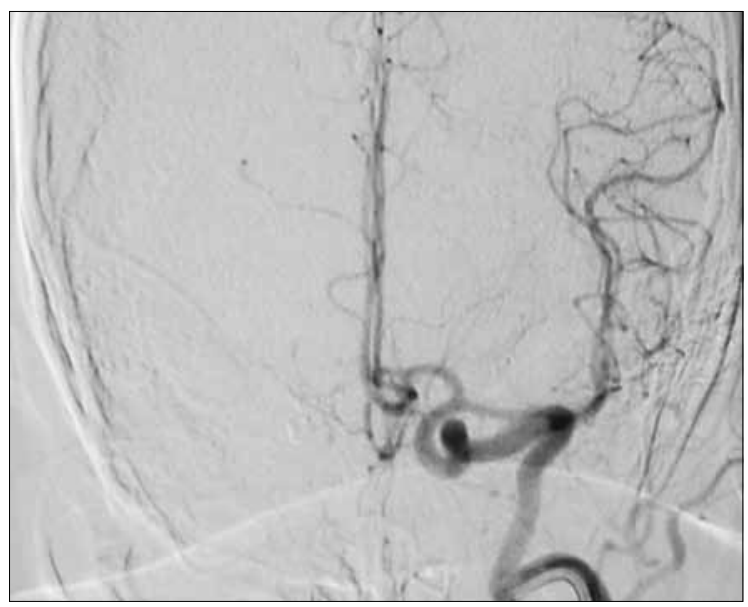

Figure 1b: Postoperative digital subtraction angiography showing exclusion of the aneurysm
Table 1: Clinical profile and location of aneurysms

\begin{tabular}{|c|c|c|c|}
\hline Age/gender & $\begin{array}{l}\text { Time since } \\
\text { ictus (days) }\end{array}$ & $\begin{array}{c}\text { Hunt and } \\
\text { hesse grade }\end{array}$ & $\begin{array}{l}\text { Location of } \\
\text { aneurysm }\end{array}$ \\
\hline $60 / F$ & 9 & I & (L) P Com \\
\hline $52 / F$ & 14 & I & $\begin{array}{l}\text { (L) P Com } \\
\text { (L) ICA bifurcation }\end{array}$ \\
\hline $32 / \mathrm{M}$ & 6 months & 1 & (L) MCA bifurcation \\
\hline 63/M & 3 & III & (R) P Com \\
\hline $50 / \mathrm{M}$ & 15 & II & A Com \\
\hline $60 / \mathrm{M}$ & 6 & IV & A Com \\
\hline $30 / \mathrm{M}$ & 28 & IV & A Com \\
\hline $37 / \mathrm{F}$ & 9 & ॥ & A Com \\
\hline 60/M & 23 & 1 & A Com \\
\hline $55 / F$ & 12 & I & $\begin{array}{l}\text { (R) P Com } \\
\text { (L) MCA bifurcation }\end{array}$ \\
\hline $57 / M$ & 10 & IV & A Com \\
\hline $38 / F$ & 12 & II & (R) MCA \\
\hline $43 / F$ & 11 & I & A Com \\
\hline $62 / \mathrm{M}$ & 16 & II & (R) P Com \\
\hline 70/F & 8 & II & A Com \\
\hline $39 / \mathrm{F}$ & 9 & I & (R) ICA bifurcation \\
\hline 29/F & 7 & III & A Com \\
\hline 48/M & 9 & 1 & (L) P Com \\
\hline $55 / \mathrm{F}$ & 13 & II & (R) MCA bifurcation \\
\hline $64 / F$ & 6 & 1 & A Com \\
\hline $58 / \mathrm{F}$ & 5 & II & A Com \\
\hline $44 / F$ & 19 & 1 & (L) MCA bifurcation \\
\hline $57 / F$ & 12 & II & A Com \\
\hline $58 / F$ & 15 & II & (R) MCA bifurcation \\
\hline $55 / \mathrm{M}$ & 12 & II & A Com \\
\hline $62 / \mathrm{F}$ & 4 & II & A Com \\
\hline $50 / \mathrm{M}$ & 7 & I & A Com \\
\hline $55 / \mathrm{M}$ & 6 & 1 & A Com \\
\hline 48/F & 12 & IV & $\mathrm{ICA}(\mathrm{L})$ \\
\hline $52 / \mathrm{M}$ & 15 & II & A Com \\
\hline 30/M & 30 & I & A Com \\
\hline $22 / \mathrm{M}$ & 22 & 1 & ICA bifurcation(L) \\
\hline $35 / \mathrm{M}$ & 30 & I & $\mathrm{ACA}(\mathrm{A} 1)$ \\
\hline $36 / \mathrm{M}$ & 6 & 1 & A Com \\
\hline $55 / \mathrm{F}$ & 12 & 1 & P Com(L) \\
\hline $60 / F$ & 15 & $\|$ & (R) MCA \\
\hline 65/M & 29 & 1 & ICA bifurcation(L) \\
\hline $44 / M$ & 12 & III & A Com \\
\hline 39/F & 4 & III & A Com \\
\hline $61 / \mathrm{F}$ & 7 & II & $\mathrm{MCA}(\mathrm{R})$ \\
\hline 67/M & 10 & II & A Com \\
\hline 37/M & 8 & IV & A Com \\
\hline $53 / \mathrm{F}$ & 17 & III & A Com \\
\hline 29/M & 3 months & I & $\mathrm{MCA}(\mathrm{L})$ \\
\hline 38/M & 6 & I & P Com(R) \\
\hline $56 / \mathrm{M}$ & 9 & II & A Com \\
\hline $33 / \mathrm{F}$ & 10 & ॥ & MCA $(L)$ bifurcation \\
\hline $55 / F$ & 30 & 1 & $\begin{array}{l}\text { MCA }(L) \text { bifurcation } \\
M C A(R) \text { bifurcation }\end{array}$ \\
\hline $60 / F$ & 30 & 1 & $\mathrm{PCom}(\mathrm{R})$ \\
\hline 43/M & 11 & II & P Com $(L)$ \\
\hline 39/F & 17 & II & A Com \\
\hline $55 / \mathrm{M}$ & 3 & I & $\mathrm{MCA}(\mathrm{L})$ bifurcation \\
\hline
\end{tabular}
cerebral artery; P Com - Posterior communicating artery

aneurysm, 10 patients had posterior communicating artery aneurysm, 11 patients had middle cerebral artery aneurysm, five patients had internal carotid artery bifurcation aneurysm, and one patient had aneurysm arising from right $\mathrm{A} 1$ segment. Four patients had more than one aneurysm: One had posterior communicating artery aneurysm on one side and middle cerebral 


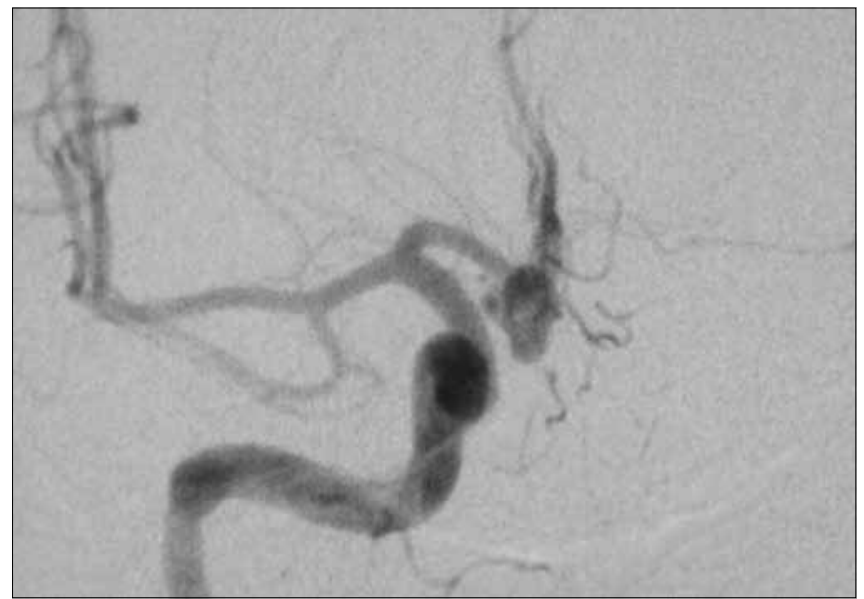

Figure 2a: Digital subtraction angiography showing multilobulated anterior communicating artery aneurysm

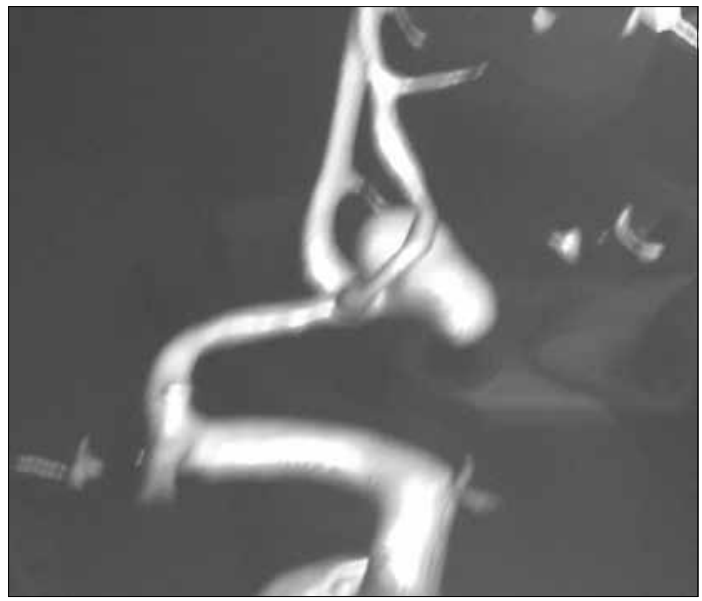

Figure 2b: 3D computed tomography showing the aneurysm

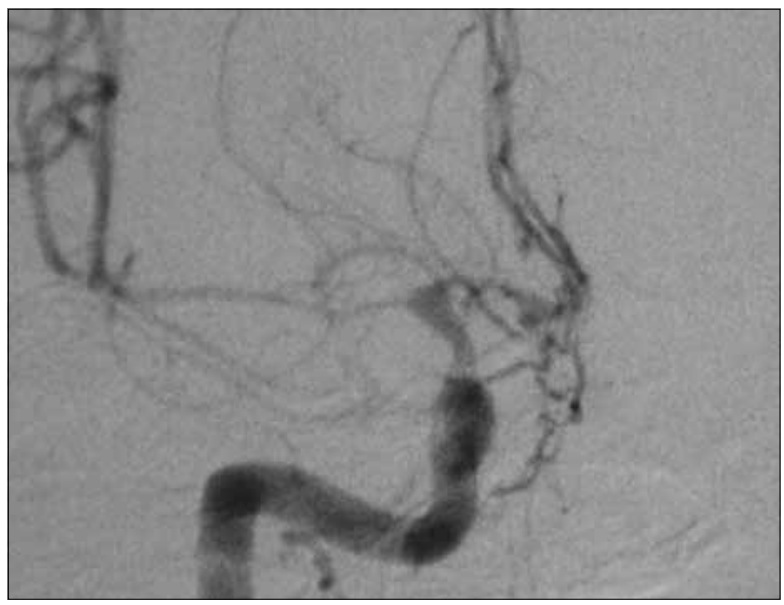

Figure 2c: Postoperative digital subtraction angiography showing exclusion of the aneurysm and spasm of middle cerebral artery

bifurcation aneurysm on the other side, second patient had ipsilateral posterior communicating and internal carotid artery aneurysms, and two patients had bilateral middle cerebral artery aneurysms.

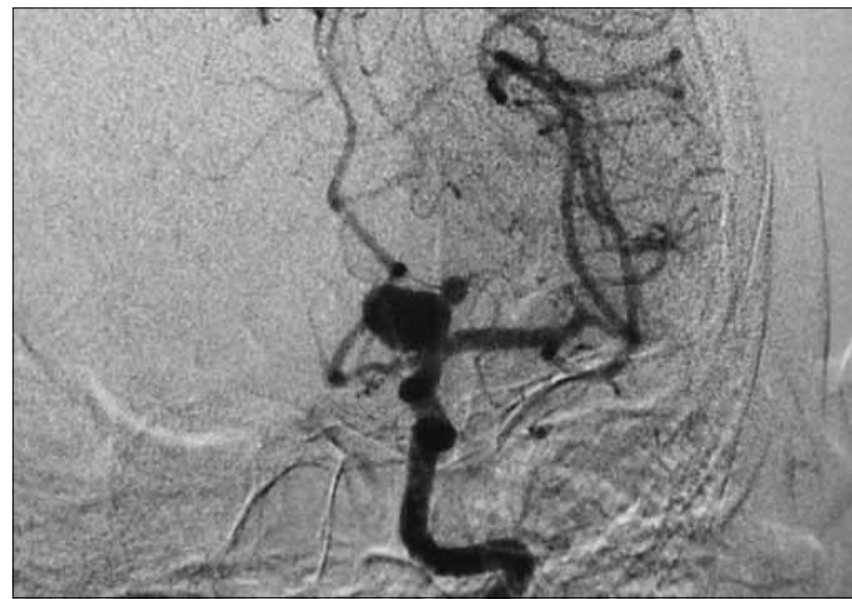

Figure 3a: Digital subtraction angiography showing internal carotid artery bifurcation aneurysm (L)

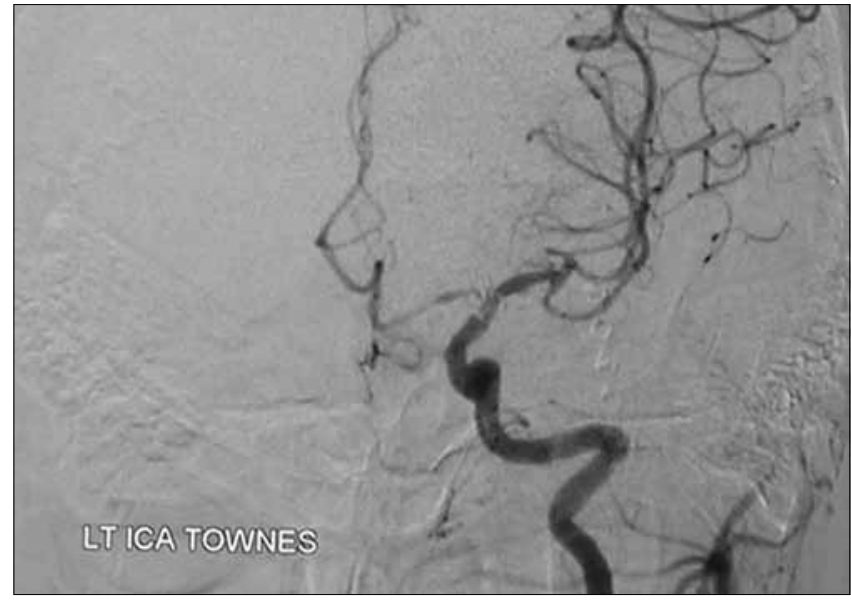

Figure 3b: Digital subtraction angiography showing clipped left ICA bifurcation aneurysm

\section{Preoperative preparation}

All patients underwent evaluation of hematological, biochemical and coagulation parameters prior to surgery. All the patients received perioperative antibiotic prophylaxis, Inj cefotaxime $1 \mathrm{~g}$ and Inj amikacin $250 \mathrm{mg}$.

\section{Positioning}

Head was placed in the extended position, and rotated to the contralateral side by 15 to 30 degrees [Figure 5]. For middle cerebral artery aneurysm, the rotation was 15 degrees while for posterior communicating and anterior communicating artery aneurysms, the rotation was 30 degrees. All right-sided aneurysms and anterior communicating artery aneurysms (irrespective of the feeding A1) were operated from the right side.

\section{Surgery}

Skin incision

The skin incision was made in the lateral two-thirds of the eyebrow, lateral to the supraorbital nerve. Extensive coagulation was avoided and skin flaps 


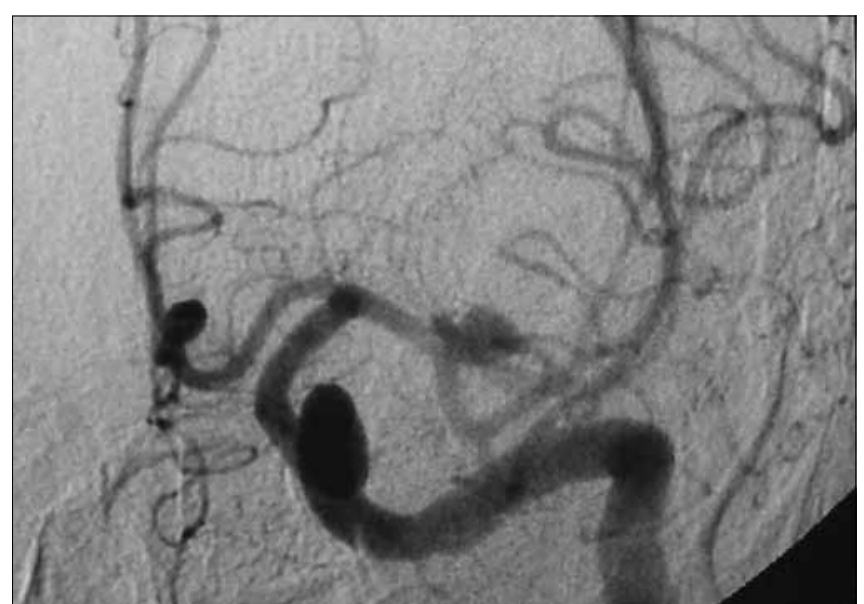

Figure 4a: Digital subtraction angiography showing left middle cerebral artery bifurcation aneurysm

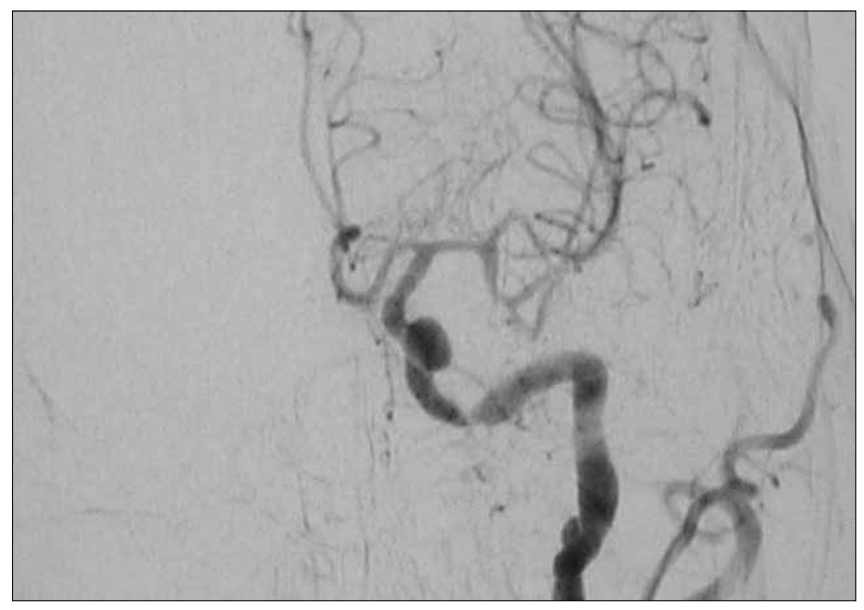

Figure 4c: Clipped middle cerebral artery aneurysm

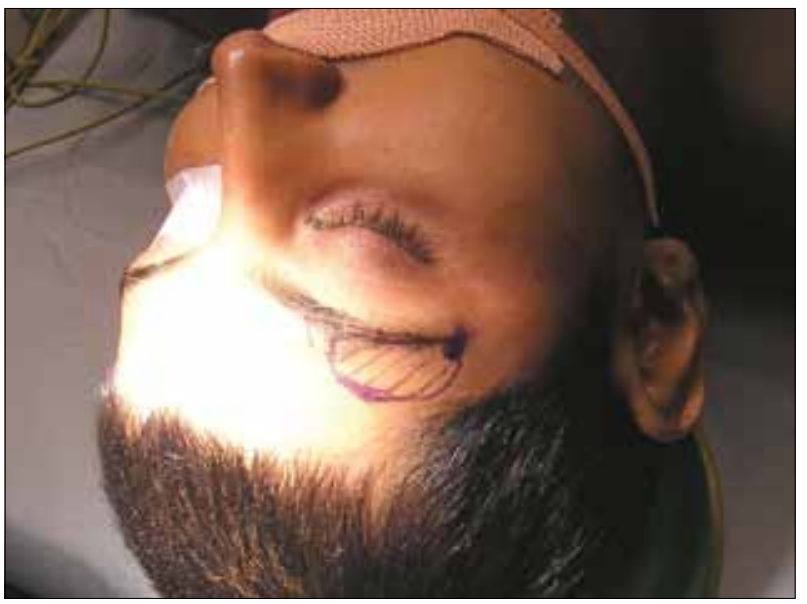

Figure 5: Transciliary incision, proposed burr-hole site and bone flap

were gently retracted. Only the superior flap was retracted and held by strong silk sutures, while care was taken not to stretch the inferior flap to avoid unpleasant postoperative orbital swelling.

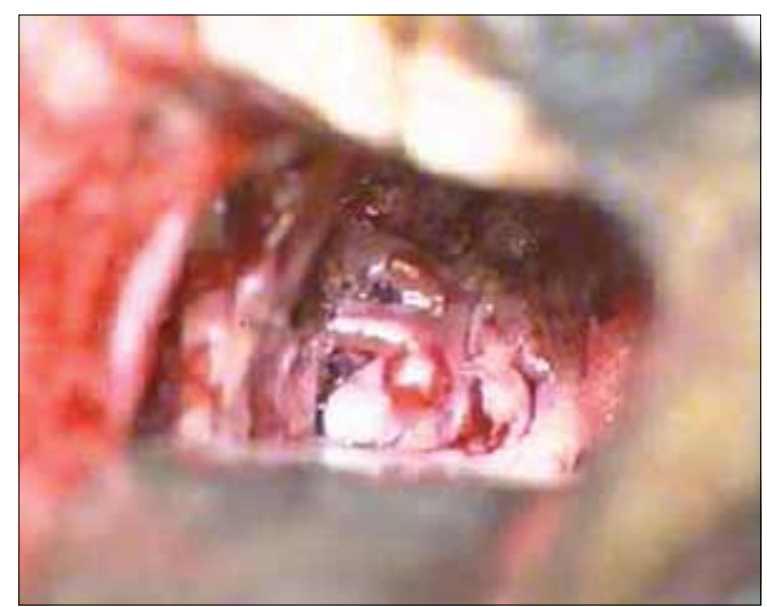

Figure 4b: Splitting of Sylvian fissure and operative exposure of the aneurysm

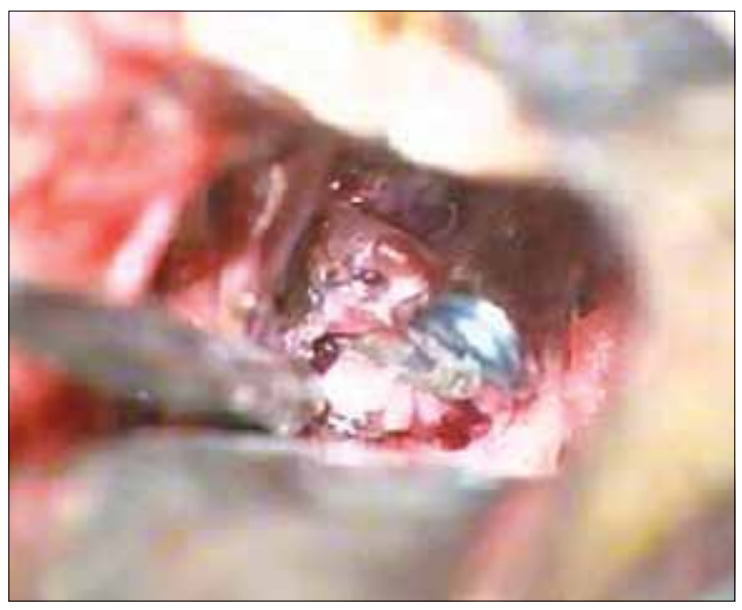

Figure 4d: Operative photograph showing clipped middle cerebral artery bifurcation aneurysm

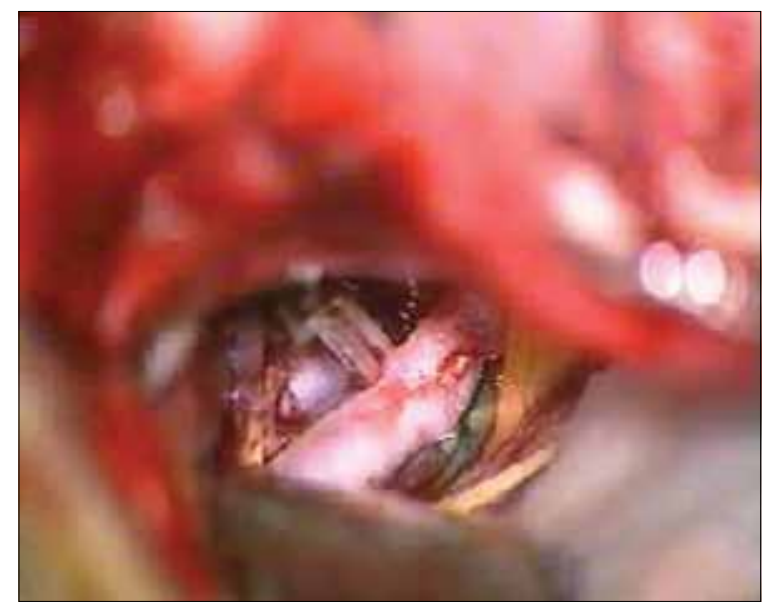

Figure 6: Operative photographs showing clipped posterior communicating artery aneurysm

Pericranium was kept intact over the orbital margin and the temporalis was separated from the superior temporal line and retracted laterally by strong silk stay sutures. 


\section{Craniotomy}

After placing one burr hole just lateral to the key-burr hole site, a free bone flap was made with craniotome, so as to make an opening nearly $2.5 \mathrm{~cm} \times 1.5 \mathrm{~cm}$, almost centrally placed on the anterior limit of the superior temporal line. It was important to make this opening flush with the floor of the anterior fossa. Inner table from the superior lip of the bony opening was removed so as to leave an internal bevel in the opening. Frontal sinus if opened, was sealed off. Dura was opened in a semilunar fashion with base at the orbital rim, and the dural flap was tented up with stay sutures. Dural margin from the superior aspect was tacked up with stay sutures.

\section{Intradural dissection}

Frontal pole was gently retracted, and cerebrospinal fluid (CSF) suction was continued till optic nerve was visualized. CSF was suctioned from carotid and chiasmatic cisterns. Arachnoid covering the Sylvian fissure was opened. The carotid, suprasellar cisterns and the Sylvian cisterns were opened to drain out CSF and to obtain further relaxation of the brain. Arachnoid strands were lysed with blunt and sharp arachnoid dissectors. Once the operative corridor was clear, one could appreciate the normal and abnormal structures and plan the steps to tackle the pathology. Discoloration due to breakdown of hemoglobin in the subarachnoid space was often evident on opening the dura. Stretch on the olfactory tract was avoided by this approach.

\section{Conduct of surgery}

Conduct of surgery required preoperative planning and appreciation of the likely problems to be encountered. There was no scope for changing plan in this approach, and even the likelihood of a catastrophe has to be kept in mind. Proximal control of the vessel had to be planned preoperatively, and conducted in a diligent and disciplined manner. Internal carotid artery exposure commenced the dissection, as it also provided proximal control in the initial stages. Early opening of carotid and Sylvian cisterns was important, and arachnoid should be lysed widely to prevent tethering effect and to relax the frontal lobe. Sylvian fissure was opened proximally, and as CSF was suctioned out, the subarachnoid spaces open, rendering the anatomy clear [Figure 4b]. Small venules in the Sylvian fissure could be coagulated, and the middle cerebral artery trunk could be followed from its origin to its bifurcation by blunt and sharp dissection. A narrow brain spatula effectively retracted the temporal lobe for middle cerebral artery aneurysm clipping [Figures $3 \mathrm{~b}$ and $4 \mathrm{~d}$ ]. Similarly, for anterior communicating artery aneurysms, both the A1 segments were displayed and readied for temporary clipping after optic, carotid and chiasmatic cisterns have been opened. Only then the aneurysm complex was dissected. Special attention was paid to preserve the perforators.
Aneurysm dissection followed the usual principles and the arachnoid dissectors, suction, bipolar coagulation, microscissors were used. Surgery required a special set of tube-shaft instruments that were long, light-weight, suitably angled and designed to function through narrow confines. The working tips had to be curved so that their shafts do not obscure vision, and the tips remained visible during cutting and dissection. With suitable positioning of the retractors, it was possible to prevent stretching or avulsion (or the planned section) of the ipsilateral olfactory tract. Position of the operating microscope was changed frequently so as to visualize all aspects of the lesion. Since the approach was small and the axis of the surgical microscope light beam and of the introduced microinstruments run almost parallel, the tips of regular instruments and clip applicators might not be adequately seen and controlled. Regular clip applicators were opened and became wider during the clipping procedure, resulting in a loss of optical control. A new clip and applicator have been developed that allowed opening the clip from within, and the tips of the applicator did not hinder the line of vision. ${ }^{[7}$ A neuroendoscope (zero degree or 30 degree) was used to see a close-up view of the operated site, and to assess the completeness of clip application. ${ }^{[1,5]}$

\section{Closure}

After meticulous hemostasis, dura was closed water-tight with running 4/0 suture. A patch of pericranium was required, reinforced by fibrin glue in case of tear in the thin basal dura. Frontal sinuses, if open, were exteriorized and sealed in the usual manner. Bone flap was fixed with a titanium miniplate. Methyl-methacrylate had been used routinely for filling the bone defect by Paladino et al. ${ }^{[5]}$

All patients underwent surgery by supraorbital keyhole approach. A total of 55 aneurysms were clipped in 52 patients. A 55-year-old female patient underwent bilateral supraorbital keyhole surgery for right-sided posterior communicating and left-sided middle cerebral artery aneurysms, and in two patients, bilateral MCA aneuryms were clipped by bilateral approach. One patient with aneurysms of posterior communicating artery segment and internal carotid artery bifurcation of the same side had clipping of both the aneurysms in the same sitting. Endoscopic assistance was not used in any of these patients. Fortynine patients underwent postoperative angiography prior to discharge.

\section{Postoperative course}

Antibiotics were administered for five days, along with other adjunctive measures like dexamethasone, and osmotic diuretics in case of brain swelling. All patients were monitored in an intensive care unit for $48 \mathrm{~h}$ after surgery. 


\section{Results}

Access was adequate in all the patients, and approach did not have to be revised in any patient. Parent vessel (internal carotid, A1 and M1) could be prepared for temporary clipping in all patients. None of the patients required drilling of anterior clinoid for proximal control. For anterior communicating artery aneurysms, the contralateral A1 could be prepared without any difficulty. Wide lysis of arachnoid and release of CSF was the key to exposure of the parent vessel, vital structures and dissection of aneurysm. Aneurysm was exposed as the last step after the parent vessel had been secured and brain was relaxed. Gyrus rectus incision and suction followed by dissection of anterior communicating artery complex displaying all the vessels could be achieved. In seven of the patients with anterior communicating artery aneurysms, fundus was directed anteriorly, while in nine of these aneurysms, the sac was directed posteriorly and inferiorly. All these aneurysms could be clipped without any difficulty, and the direction of the fundus was of no consequence. Complete aneurysm was dissected in 23 patients, while in the rest, clip was applied first across the neck and then the aneurysm was dissected completely. Aneurysm size was between 4 and $12 \mathrm{~mm}$. On 12 occasions, there was intraoperative rupture, two at the time of neck dissection (PCom) and 10 at the time of clip application (Acom 9, MCA 1). All 12 could be tackled without any problem, details of which are described in discussion. Length of middle cerebral artery was of no relevance to the approach; three of the patients had a 2-cm-long parent M1 and the aneurysm could be exposed without any problem.

\section{Clinical outcome}

The outcome was no disability or mild disability (Glasgow outcome scale (GOS) (5 and 4) in 43 patients. Four patients who were in Grade IV preoperatively died in the postoperative period due to vasospasm.

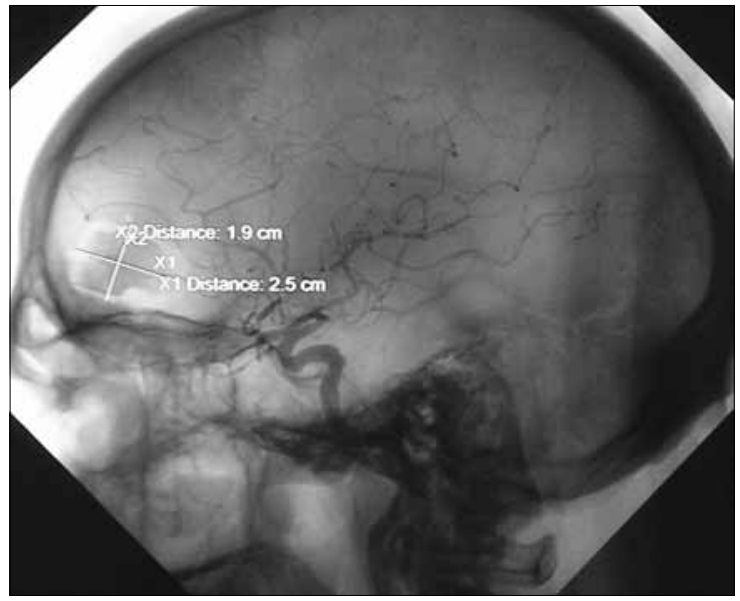

Figure 7: Skull radiograph showing size of craniotomy
Five patients worsened due to vasospasm, but recovered over the next two weeks. Postoperative angiography in 47 patients revealed that aneurysm clipping was complete [Figures 1b, 2c, 3b, 4c, 6]. Check-angiography could not be done in four patients who died in the postoperative period. No patient required any other procedure, wrapping or revision of the approach. Postoperative hospital stay was seven days in 43 patients.

\section{Cosmetic results}

Patients were overall satisfied with their appearance, and were happy to have avoided head shave [Figures 7 and 8]. Two patients had postoperative orbital swelling which lasted for five days. While there was no depression of the operated site, in one patient, the eyebrow had become high arched and asymmetrical as compared to the opposite side.

\section{Follow-up}

Forty-eight patients have been followed up over six months to five years (mean 21 months). There have been no instances of wound infection, recurrent hemorrhage or neurological worsening. Seven patients complained of numbness lasting nearly six months over the frontal scalp on the side of surgery. Two patients were seen to have flattening of forehead furrowing, indicating frontalis nerve injury.

\section{Discussion}

Management of intracranial aneurysms by endovascular procedures is gradually becoming the standard practice in many neurosurgical centers the world over. Microneurosurgical procedures however, continue to be followed in most of the centers where endovascular procedures are not available, or are more expensive than open microneurosurgical procedures. Long-term results of coiling of intracranial aneurysms will be

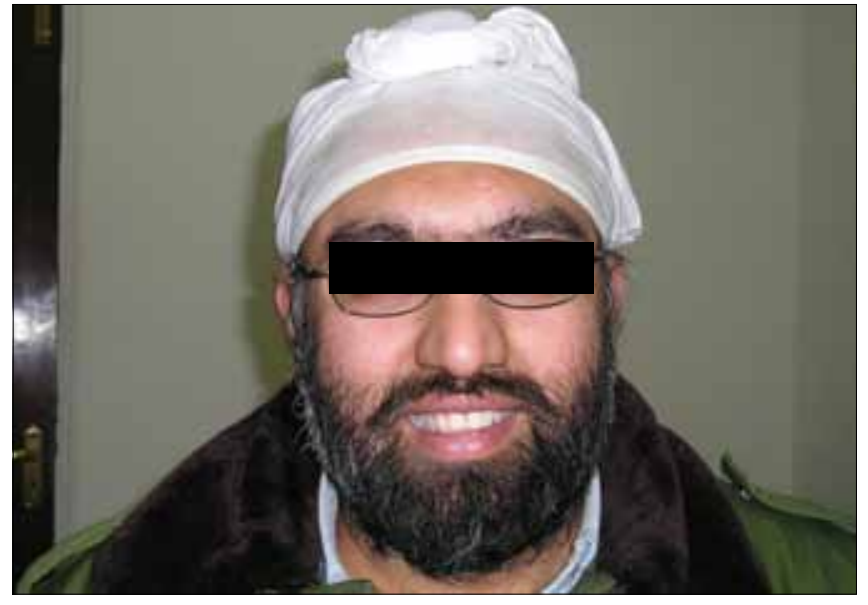

Figure 8: Postoperative appearance in a patient 
apparent as these patients are followed up, and it is likely that number of patients requiring clipping following endovascular procedures will show a rise. ${ }^{[8-10]}$ The role of microneurosurgery in the management of intracranial aneurysms is well established and neurosurgeons will have to remain well versed in the art and technique of aneurysm clipping. In the old description of transcranial surgery for intracranial aneurysms, large exposure was the standard practice, even if only to reach the suprasellar or parasellar area, which is only about $3 \mathrm{~cm}$ across. Introduction of operating microscope did not bring about an immediate reduction of the size of craniotomy, and it has taken an entire generation of neurosurgeons to make keyhole surgery a standard treatment of lesions in the suprasellar and parasellar region. Today, a number of keyhole approaches are available, each one giving a different angle of maneuverability and vision, which can tackle all anterior circulation aneurysms. The approach can tackle contralateral aneurysms as well, ${ }^{[2,7]}$ although Czirjajk et al., ${ }^{[11]}$ and Mitchell et al., ${ }^{[3]}$ preferred to operate through bilateral supraorbital approaches in patients with bilateral aneurysms. Clinical outcome after aneurysm clipping by keyhole approach has been found to be same as that after standard craniotomy. ${ }^{[4]}$ The learning curve is short and does not entail acquisition of new concepts. Use of endoscope is optional.

Since 2003, we have used the eyebrow keyhole craniotomy as operative approach to the aneurysms of the Anterior cerebral artery (ACA)/ anterior communicating artery (ACoA )complex, supraclinoid and ophthalmic segments of the internal carotid artery (ICA) and middle cerebral artery bifurcation. In our experience, length of M1 segment is not important while deciding to tackle MCA aneurysm by keyhole approach.

A neurosurgeon graduates to minimalism (frontotemporal-pterional-minicraniotomy) as he/ she becomes familiar with the microanatomy of the region concerned. Keyhole craniotomy, like neuroendoscopy is the culmination of interplay of knowledge neuroanatomy, the nature of pathological lesion, optics and instrumentation, and operative neurosurgical skills. From time to time, this procedure has been subjected to scrutiny by experts in vascular and skull base neurosurgery. One common objection is the limited access and scope for maneuverability during aneurysm dissection. The key to the problem is a thorough familiarity with microanatomy learned on cadavers. One evolves with the procedures as much as the procedure evolves over a period of time. Case selection is certainly important, as is a critical self-appraisal of one's ability to work in narrow, confined spaces. Introduction of tube-shaft instruments for dissection and clip application has made this procedure possible. Wide opening of arachnoid spaces, including Sylvian fissure is mandatory to achieve relaxation of the brain, and passage to the aneurysm location. ${ }^{[1]}$ Retraction is less than what is made in a standard craniotomy (where the site of pathology lies at the apex of the funnel of view even with an operating microscope). We have been able to preserve olfaction without having to dissect the olfactory tract in 45 of our patients. None of our patients had to undergo osteotomy of the orbital rim, or drilling of anterior clinoid.

Another major objection to this procedure has been the fear of having to tackle intraoperative aneurysm rupture in narrow, confined space. Again, the key to the problem lies in wide arachnoid dissection before tackling the aneurysm, having prepared self and the proximal feeder vessel for temporary clipping, and most important, managing with "two hands" instead of "three hands" in the operative field. Temporary clipping of the feeder vessel with one hand as the other hand keeps the field clear with suction nozzle placed directly close to the aneurysm-often covered with a small pattie, can be accomplished. On two occasions, we could temporarily clip both A1 vessels and apply clip on anterior communicating artery aneurysm. We often carry out "temporary clipping practice" of the vessels concerned prior to aneurysm dissection, so that the placement of the temporary clip is smooth if the aneurysm ruptures while dissecting or clipping. A swollen brain can be made lax by opening of the Sylvian, carotid and chiasmatic cisterns. Other objections like direction of the fundus, the length of M1 segment in aneurysms of middle cerebral artery, etc have not been of much consequence. Cosmetic considerations too are important, and an incision in the eyebrow gets concealed in a few weeks after surgery: We have avoided excessive coagulation over the incision margins to prevent eyebrow alopecia.

Since intracranial aneurysms (including some of those treated endovascularly) will continue to be clipped for times to come, the concept of minimally invasive keyhole approach for anterior circulation aneurysms should remain within the armamentarium of neurosurgery. Endovascular techniques (the technique, expertise and equipment) are not yet universally available. The transciliary supraorbital keyhole approach can be regarded as a standard for clipping of various anterior circulation aneurysms. Compared to standard craniotomy, incision is small, there is a smaller bone window with requirement for distinct microneurosurgical techniques and instrumentation, and the approach can be combined with neuroendoscopy. ${ }^{[12]}$ There is no need for osteotomy of the supraorbital rim. Brain exposure to non- 
physiological environment is less, and there is lesser postoperative orbitofacial swelling with excellent cosmetic results. While the postoperative course is smooth and hospital stay is short, there are no distinct limitations or disadvantages of the approach while clipping anterior circulation aneurysms.

\section{References}

1. van Lindert E, Perneczky A, Fries G, Pierangeli E. The supraorbital keyhole approach to supratentorial aneurysms: Concept and technique. Surg Neurol 1998;49:481-90.

2. Martellotta N, Gigante N, Toseano S, Maddalena GF, Tripodi M, Settembrini G, et al. Unilateral supraorbital keyhole approach in patients with middle cerebral artery (M1-M2 segment) symmetrical aneurysms. Minim Invasive Neurosurg 2003;46:228-30.

3. Mitchell P, Vindlacheruva RR, Mahmood K, Ashpole RD, Grivas A, Mendelow AD. Supraorbital eyebrow minicraniotomy for anterior circulation aneurysms. Surg Neurol 2005;63:47-51.

4. Paladino J, Mrak G, Miklic, Jednacak, Mihaljevic D. The keyhole concept in aneurysm surgery. A comparative study: Keyhole versus standard craniotomy. Minim Invasive Neurosurg 2005;48:250-8.

5. Paladino J, Pirker N, Stimac D, Stern-Padovan R. Eyebrow keyhole approach in vascular neurosurgery. Minim Invasive Neurosurg
$1998 ; 41: 200-3$.

6. Hernesniemi J, Ishii K, Niemelä M, Smrcka M, Kivipelto L, Fujiki M, et al. Lateral supraorbital approach as an alternative to the classical pterional approach. Acta Neurochir Suppl 2005;94:17-21.

7. Perneczky A, Fries G. Use of a new aneurysm clip with an inverted-spring mechanism to facilitate visual control during clip application: Technical note. J Neurosurg 1995;82:898-9.

8. König RW, Kretschmer T, Antoniadis G, Seitz K, Braun V, Richter HP, et al. Neurosurgical management of previously coiled recurrent intracranial aneurysms. Zentralbl Neurochir 2007;68:8-13.

9. Raja PV, Huang J, Germanwala AV, Gailloud P, Murphy KP, Tamargo RJ. Microsurgical clipping and Endovascular coiling of intracranial aneurysms. A critical review of the literature. Neurosurgery 2008;62:1187-203.

10. Veznedaroglu E, Benitez RP, Rosenwasser RH. Surgically treated aneurysms previously coiled: Lessons learnt. Neurosurgery 2004;54:300-3.

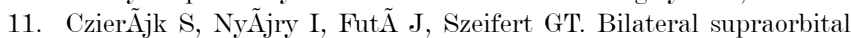
keyhole approach for multiple aneurysms via superciliary incisions. Surg Neurol 2002;57:314-23.

12. Reisch R, Perneczky A. Ten-year-experience with the supraorbital approach through an eyebrow skin incision. Neurosurgery $2005 ; 57: 242-55$.

Accepted on 10-08-2009

Source of Support: Nil, Conflict of Interest: None declared.

\section{Dispatch and return notification by E-mail}

The journal now sends email notification to its members on dispatch of a print issue. The notification is sent to those members who have provided their email address to the association/journal office. The email alerts you about an outdated address and return of issue due to incomplete/incorrect address.

If you wish to receive such email notification, please send your email along with the membership number and full mailing address to the editorial office by email. 